OPEN ACCESS

Edited by:

Dietmar Thurnher,

Medical University of Graz, Austria

Reviewed by:

Maria Grazia Ghi,

Veneto Institute of Oncology (IRCCS),

Italy

Weiren Luo,

The Second Affiliated Hospital of Southern University of Science and

Technology, China

*Correspondence:

Danny Rischin

Danny.Rischin@petermac.org

Specialty section:

This article was submitted to Head and Neck Cancer.

a section of the journal

Frontiers in Oncology

Received: 21 January 2021 Accepted: 22 March 2021

Published: 15 April 2021

Citation:

Lim AM, Cavanagh K, Hicks RJ,

McLean L, Goh MS, Webb A and Rischin D (2021) Delayed Response After Confirmed Progression (DR) and Other Unique Immunotherapy-Related

Treatment Concepts in Cutaneous

Squamous Cell Carcinoma.

Front. Oncol. 11:656611.

doi: 10.3389/fonc.2021.656611

\section{Delayed Response After Confirmed Progression (DR) and Other Unique Immunotherapy-Related Treatment Concepts in Cutaneous Squamous Cell Carcinoma}

\author{
Annette M. Lim ${ }^{1,2}$, Karda Cavanagh ${ }^{3}$, Rodney J. Hicks ${ }^{4}$, Luke McLean ${ }^{1}$, Michelle S. Goh ${ }^{5}$, \\ Angela Webb ${ }^{6}$ and Danny Rischin ${ }^{1,2^{\star}}$ \\ ${ }^{1}$ Department of Medical Oncology, Peter MacCallum Cancer Centre, Melbourne, VIC, Australia, ${ }^{2}$ Sir Peter MacCallum \\ Department of Oncology, Faculty of Medicine, Dentistry and Health Sciences, The University of Melbourne, VIC, Australia, \\ ${ }^{3}$ Department of Cancer Imaging, Peter MacCallum Cancer Centre, Melbourne, VIC, Australia, ${ }^{4}$ Department of Nuclear \\ Medicine, Peter MacCallum Cancer Centre, Melbourne, VIC, Australia, ${ }^{5}$ Department of Dermatology, Peter MacCallum \\ Cancer Centre, Melbourne, VIC, Australia, ${ }^{6}$ Department of Plastic Surgery, Peter MacCallum Cancer Centre, Melbourne, \\ VIC, Australia
}

Non-melanoma skin cancers are one of the most common cancers diagnosed worldwide, with the highest incidence in Australia and New Zealand. Systemic treatment of locally advanced and metastatic cutaneous squamous cell carcinomas has been revolutionized by immune checkpoint inhibition with PD-1 blockade. We highlight treatment issues distinct to the management of the disease including expansion of the traditional concept of pseudoprogression and describe delayed responses after immune-specific response criteria confirmed progressive disease with and without clinical deterioration. We term this phenomenon "delayed response after confirmed progression (DR)". We also discuss the common development of second primary tumors, heterogeneous disease responses, and expanding clinical boundaries for immunotherapy use.

\footnotetext{
Keywords: immunotherapy, PD-1 inhibition, pseudoprogression, cutaneous squamous carcinoma, second primary tumors (SPTs)
}

\section{INTRODUCTION}

Non-melanoma skin cancers (NMSC) predominantly basal cell carcinomas (BCC) and cutaneous squamous cell carcinomas (CSCC) are the most frequently diagnosed cancer in North America and Australia/New Zealand (1). Although most are resectable, the morbidity related to disease is significant and accounts for the most common cancer-related cause for hospitalization in Australia exacerbated by the multiplicity of skin cancer excisions (2-4). Approximately $5 \%$ of CSCC recur or metastasize leading to death or management associated with significant morbidity due to disease occurrence on sun-exposed areas such as the face, head and neck $(5,6)$.

In 2018, the first report of the efficacy of cemiplimab, a PD-1 inhibitor, was published for the treatment of patients with locally advanced or metastatic CSCC who were not candidates for curative surgery or radiation. The objective response rate (ORR) to therapy was $47 \%$ (range: $34-61$ ), 
leading to Food and Drug Administration (FDA) and European Medicines Agency (EMA) approval and a paradigm shift in the management of these tumors $(7,8)$. Updated data indicates that the median duration of response and median overall survival (OS) have not been reached, with estimated 24 month-OS being 73.3\% (95\% CI: 66.1-79.2) (9). The KEYNOTE-629 study showed that pembrolizumab is also efficacious (ORR 34\%; 95\% CI: 25- 44) (10), which also led to FDA approval. First line pembrolizumab in the CARSKIN trial for locally advanced or metastatic CSCC (including radiotherapy naive patients, $\mathrm{n}=20$ / 57) achieved a week 15 ORR of 41\% (95\% CI: 26-58\%) (11). Therefore, the use of PD-1 blockade for the treatment of advanced CSCC represents a major breakthrough in the management of these common epithelial cancers.

We report our immunotherapy management experiences unique to CSCC that challenge and expand current clinical concepts in practice.

\section{EXPANDING ON THE CONCEPT OF PSEUDOPROGRESSION - "DELAYED RESPONSES AFTER CONFIRMED PROGRESSION (DR)" AND RESPONSE AFTER CLINICAL DETERIORATION}

The Response Evaluation Criteria in Solid Tumors (RECIST) criteria is a validated measure for the standardized evaluation of cancer therapies, determined by the assessment of the change of tumor burden with treatment (12). There are notable limitations of the RECIST guidelines in patients treated with immunotherapy, given that "pseudoprogression" can occur with an increase in tumor size due to inflammatory cell infiltrates followed by tumor reduction (13), and improved OS can occur without RECIST defined reduction in tumor measurements (14-16). Thus, RECIST criteria have been modified to include immune-related response criteria (irRC), immune-related response evaluation criteria in solid tumors (irRECIST), modified RECIST1.1 for immunotherapy (iRECIST), and immune-modified RECIST (imRECIST) (17-20).

Pseudoprogression occurs in under $10 \%$ of all cancers treated with immunotherapy, with an incidence in head and neck cancer of approximately 1\% (21-24). To address pseudoprogression, the irRC, irRECIST and iRECIST require the use of confirmatory imaging at least 4 weeks after initial progression is documented (we will refer to this collectively as iCPD, immune confirmed disease progression as per iRECIST), a minimum size increase of $>5 \times 5 \mathrm{~mm}^{2}$ or $10 \mathrm{~mm}$, an increase in the sum of tumor measurements from the nadir of 20-25\%, and incorporation of new lesions in the sum of tumor dimension measurements before confirmation of progressive disease (PD) (17-19). The imRECIST criteria is similar, but permits the best response assessment to occur after observation of progressive disease, which avoids underestimation of survival rates (20). All criteria recommend that treatment beyond progression should only occur if a patient's performance status and disease-related symptomatology are stable.

We describe two cases to redefine our understanding of pseudoprogression, with delayed disease response observed after iCPD and after observation of clinical deterioration. We introduce new terminology to capture the phenomenon as "delayed response after confirmed progression (DR)". We also discuss a case of tumor response observed in a patient with clinical deterioration, with treatment beyond progression.

\section{Case One}

This case illustrates the observation of DR. Patient One was diagnosed with a T2N0M0 occipital scalp/vertex CSCC excised with clear margins in September 2017. In July 2018, a 35mm intransit recurrence was resected with an involved margin. Reexcision and ipsilateral neck dissection demonstrated a $2.5 \mathrm{~mm}$ residual CSCC $1.2 \mathrm{~mm}$ from the deep margin, and $1 / 41$ nodes involved with extranodal extension to the surgical margin. Adjuvant radiotherapy of $66 \mathrm{~Gy} / 33$ \# was completed in October 2018. Within three weeks, biopsy of multiple new in-field intransit CSCC and an out-of-field intramuscular lesion confirmed recurrent disease. Following multidisciplinary meeting (MDM) discussion, he was referred for consideration of immunotherapy for his recurrent CSCC.

The patient was enrolled on the NCT02760498 to receive cemiplimab 400mg Q4W, with RECIST 1.1 measurements determined by radiological assessments as per protocol. The progression of lesions documented by photography, and radiological assessments are summarized in Figures 1A, B. Four weeks after initial dose, Patient One reported worsening disease-related pain. The largest CSCC lesion had increased by $10 \mathrm{~mm}$ with new ulceration (black arrow), other baseline lesions had also increased in size with ulceration, while at least three new lesions greater than $10 \mathrm{~mm}$ had developed with multiple other smaller lesions visible. This corresponded to unconfirmed progressive disease (iUPD). Four weeks later prior to his third dose, ongoing progression was noted with further ulceration and coalescence of lesions (white checked arrow), and increasing size of new nodules by more than $10 \mathrm{~mm}$ (black spotted arrow) confirming iCPD. At that time point, RECIST 1.1 assessment by imaging confirming PD (Figure 1B). Approval for treatment beyond progression was granted. By the next visit, all lesions had improved clinically with a reduction in size and improvement in pain. The patient completed 12 months of therapy with a complete clinical response. To date, the patient remains in clinical and radiological remission.

\section{Case Two}

This case illustrates DR. Patient Two had a long history of multiple NMSC lesions being excised from the head, neck, and chest, including a Merkel cell carcinoma (MCC). Patient Two had a CSCC lesion from the left clavicular area that required multiple re-excisions over a six-month period before clear margins were achieved in January 2018. In May 2018, a left infraclavicular chest recurrent CSCC was excised that involved 
A
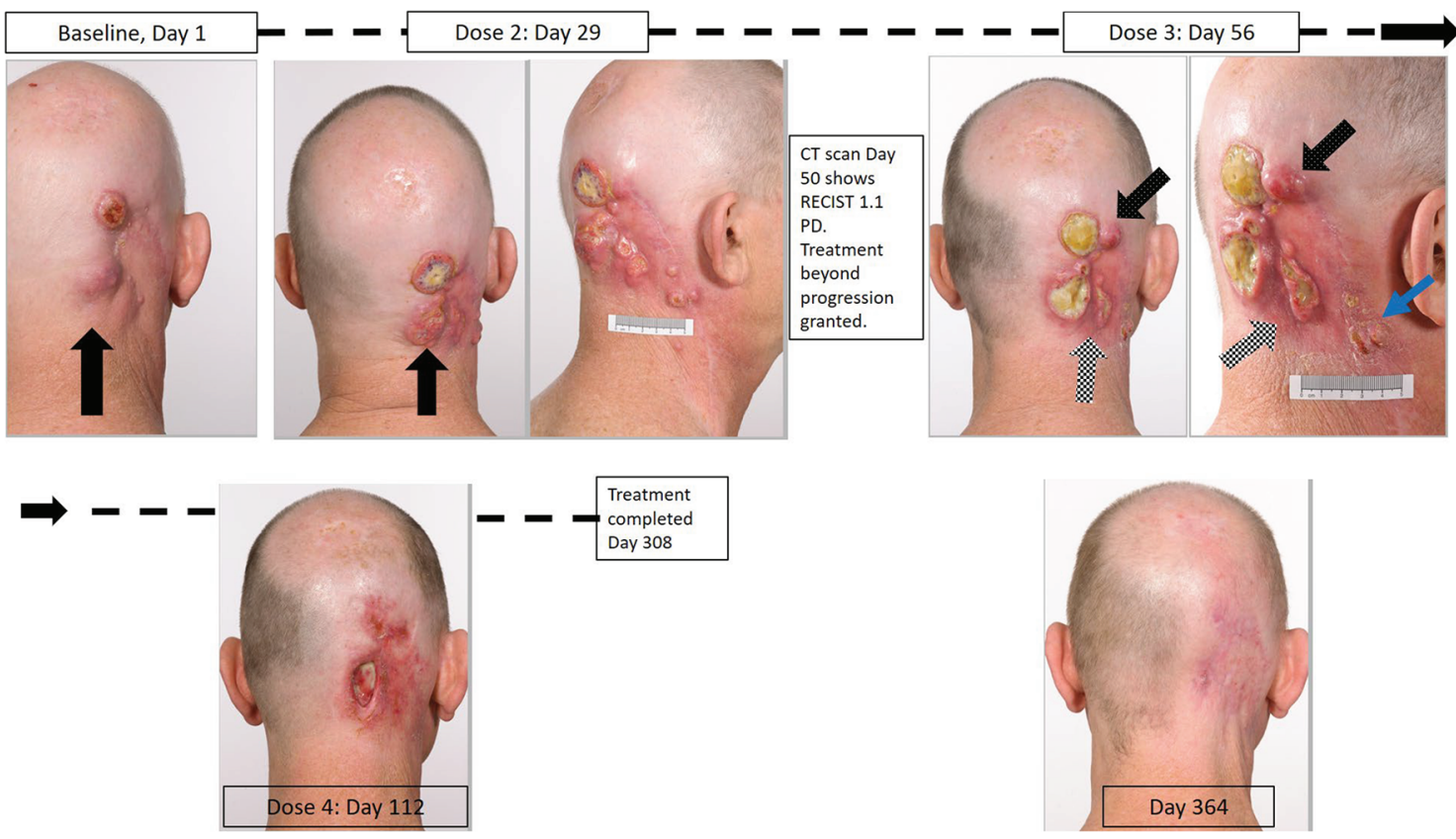

B

\begin{tabular}{|c|c|c|c|c|c|c|c|c|c|c|}
\hline \multicolumn{2}{|c|}{$\begin{array}{l}\text { Target Lesion Site } \\
\text { (in } \mathrm{mm} \text { ) }\end{array}$} & \begin{tabular}{|l} 
Baseline \\
RECIST
\end{tabular} & \begin{tabular}{|c|} 
Clinic review \\
Dose 2 \\
Day 28
\end{tabular} & $\begin{array}{c}C T \\
\text { Day } 50\end{array}$ & $\begin{array}{l}\text { Clinic review } \\
\text { Dose } 3 \\
\text { Day } 56\end{array}$ & $\begin{array}{c}\text { CT } \\
\text { Day } 108\end{array}$ & $\begin{array}{c}\text { CT } \\
\text { Day } 167\end{array}$ & $\begin{array}{c}\text { CT } \\
\text { Day } 335\end{array}$ & \begin{tabular}{|c|} 
CT \\
Day 386 \\
Follow up 2 \\
months
\end{tabular} & $\begin{array}{c}\text { CT } \\
\text { Day } 442 \\
\text { Follow up } 4 \\
\text { months }\end{array}$ \\
\hline A & $\begin{array}{l}\text { Right paraoccipital } \\
\text { subcutaneous lesion }\end{array}$ & $31 \times 21$ & $\begin{array}{c}\text { Progression, } \\
\text { ulceration, } \\
\text { increased pain }\end{array}$ & $37 \times 29$ & $\begin{array}{l}\text { Progression, } \\
\text { ulceration, } \\
\text { increased pain }\end{array}$ & $29 \times 20$ & $25 \times 18$ & $16 \times 6$ & $\begin{array}{c}\text { Too small to } \\
\text { measure } \\
\text { default } 5 \mathrm{~mm}\end{array}$ & $\begin{array}{l}\text { Too small to } \\
\text { measure } \\
\text { default } 5 \mathrm{~mm}\end{array}$ \\
\hline B & $\begin{array}{l}\text { Right neck } \\
\text { intramuscular deposit }\end{array}$ & $14 \times 10$ & \begin{tabular}{|c|} 
Confluent \\
progression with \\
other lesions
\end{tabular} & $17 \times 15$ & $\begin{array}{l}\text { Progression, } \\
\text { ulcerated, } \\
\text { increased pain }\end{array}$ & $12 \times 12$ & 0 & 0 & 0 & 0 \\
\hline \multicolumn{2}{|c|}{ Total (Target) mm } & 45 & & 54 & & 41 & 25 & 16 & 5 & 5 \\
\hline \multicolumn{2}{|c|}{$\begin{array}{l}\% \text { change from baseline } \\
\% \text { change from re-baseline after iUPD }\end{array}$} & NA & & +20 & & $\begin{array}{c}-9 \\
-24\end{array}$ & $\begin{array}{l}-44 \\
-53\end{array}$ & $\begin{array}{l}-64 \\
-70\end{array}$ & $\begin{array}{l}-89 \\
-91\end{array}$ & $\begin{array}{l}-89 \\
-91\end{array}$ \\
\hline \multicolumn{2}{|c|}{ Non-Target Lesion Site } & & \multicolumn{8}{|c|}{ Present (P) or Absent (A) } \\
\hline \multicolumn{2}{|c|}{1 Dermal deposits right neck } & Present & & Present & & Present & Absent & Absent & Absent & Absent \\
\hline & New lesions & & At least $3 \times 10 \mathrm{~mm}$ & $\begin{array}{l}\text { Yes, } \\
\text { multiple } \\
\text { new scalp } \\
\text { and neck }\end{array}$ & $\begin{array}{l}\text { Increased further } \\
\text { by }>20 \mathrm{~mm} \text { but no } \\
\text { new lesions }\end{array}$ & No & No & No & No & No \\
\hline \multicolumn{2}{|c|}{$\begin{array}{l}\text { Overall Response } \\
\text { RECIST } 1.1\end{array}$} & & PD & PD & PD & PD & PD & PD & PD & PD \\
\hline \multicolumn{2}{|c|}{$\begin{array}{l}\text { Including clinical assessments } \\
\text { iRECIST } \\
\text { irRECIST } \\
\text { imRECIST }\end{array}$} & & $\begin{array}{l}\text { IUPD } \\
\text { iUPD } \\
\text { iUPD }\end{array}$ & $\begin{array}{l}\text { iCPD } \\
\text { iCPD } \\
\text { iCPD }\end{array}$ & $\begin{array}{l}\text { ICPD } \\
\text { iCPD } \\
\text { iCPD }\end{array}$ & $\begin{array}{l}\text { iCPD } \\
\text { iCPD } \\
\text { iSD }\end{array}$ & $\begin{array}{l}\text { iCPD } \\
\text { iCPD } \\
\text { iPR }\end{array}$ & $\begin{array}{l}\text { iCPD } \\
\text { iCPD } \\
\text { iPR }\end{array}$ & $\begin{array}{l}\text { iCPD } \\
\text { iCPD } \\
\text { iPR }\end{array}$ & $\begin{array}{l}\text { iCPD } \\
\text { iCPD } \\
\text { iPR }\end{array}$ \\
\hline
\end{tabular}

FIGURE 1 | Continued 

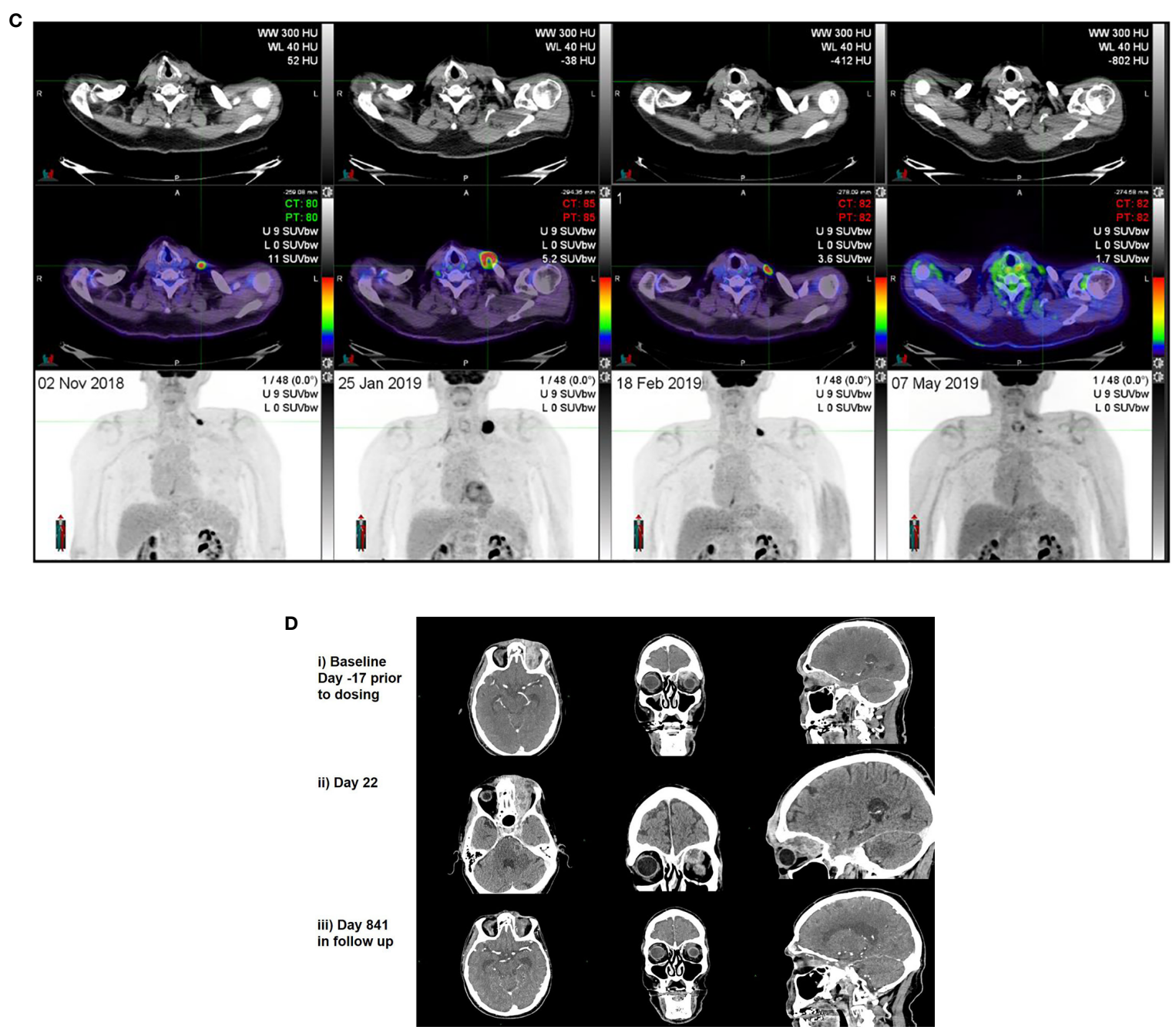

FIGURE 1 | Correlative clinical photographs, tumor response measurements according to time, and fluorodeoxyglucose - positron emission tomography (FDG-PET) and CT scan images of discussed patient cases. (A, B) Patient One's photographic images demonstrating iUPD and iCPD, with accompanying tumor response measurements according to RECIST 1.1 and immune based criteria at key time points. (C) Patient Two's FDG-PET images over time with low dose axial CT, fused axial CT, and maximal intensity projection (MIP) images in each column from 02/NOV/2018, 25/JAN/2019, 18/FEB/2019, and 07/MAY/2019, demonstrating evidence of progression and regression with ongoing immunotherapy. (D) Patient Three's representative images of disease at baseline, at progression and with response. Images i) Baseline (Day-17 prior to dosing) Post contrast CT: (axial, coronal, sagittal) demonstrates enhancing soft tissue extending from the cutaneous left forehead along the roof of the left orbit in the distribution of $\mathrm{V} 1$, involving the cavernous sinus, Meckel's cave, nerve root entry zone of the left trigeminal nerve and likely involvement of the trigeminal nuclei with soft tissue at the left pons. ii) Day 22 Post contrast CT: (axial, coronal, sagittal) demonstrates increasing volume of enhancing soft tissue extending from the cutaneous left forehead along the roof of the left orbit in the distribution of $\vee 1$, involving the cavernous sinus, Meckel's cave, nerve root entry zone of the left trigeminal nerve and involvement of the trigeminal nuclei with soft tissue at the left pons. iii) Day 841 (in follow up) Post contrast CT: (axial, coronal, sagittal) demonstrates small volume residual non-enhancing soft tissue extending from the cutaneous left forehead along the roof of the left orbit. The remaining soft tissue has resolved on CT.

the clavicular head of the pectoralis major muscle and pathologically measured $32 \mathrm{~mm}$ with a deep margin of $0.7 \mathrm{~mm}$ and evidence of perineural invasion. Re-excision demonstrated no residual disease but another $0.3 \mathrm{~mm}$ central chest poorly differentiated carcinoma of uncertain origin was concurrently excised with clear margins. Adjuvant radiotherapy of 60Gy/30\# was completed on August 2018. Two months later, a biopsy of a nodule over the medial aspect of the left clavicle confirmed recurrent CSCC. Magnetic resonance imaging (MRI) and computer tomography (CT) scans were unable to define the lesion, but fluorodeoxyglucose positron emission tomography (FDG-PET) scan identified an $\sim 13 \mathrm{~mm}$ left supraclavicular lesion (Figure 1C). After MDM discussion, Patient Two was referred for consideration of immunotherapy. Given his history of MCC, he was ineligible for trial participation and self-funded pembrolizumab 200mg Q3W which commenced on 28/NOV/ 2018. At review prior to the second dose (19/DEC/2018), his lesion had increased by more than $10 \mathrm{~mm}$ to $\sim 40 \mathrm{x} 30 \mathrm{~mm}$ with 
purpuric discoloration of the intact skin consistent with iUPD. By review prior to the third dose (08/JAN/2019), the lesion had fungated through the skin. A restaging FDG-PET scan (25/JAN/ 2019) performed after administration of three doses of pembrolizumab demonstrated marked interval progression with increase in size of disease to $33 \mathrm{~mm}$ confirming iCPD (+254\%). On 29/JAN/2019, iCPD was confirmed clinically and the fourth dose of immunotherapy was abandoned and surgical salvage was planned. Two weeks later prior to surgery, the patient reported clinical improvement and repeat imaging performed $(18 / \mathrm{FEB} / 2019)$ demonstrated reduction in tumor size to $15 \mathrm{~mm}$ ( $-55 \%$ from previous). Pembrolizumab was resumed and by the subsequent visit, he had obtained a complete clinical response. Approximately 12 months of treatment was completed on $02 / \mathrm{JAN} / 2020$ and the patient remains in complete metabolic, radiological and clinical response to date.

\section{Case Three}

This case highlights that clinical deterioration may not militate against disease response with the use of immunotherapy for the treatment of CSCC. Patient Three had a long history of multiple NMSC and at age 81 years was diagnosed with a T4N0M0 left supraorbital/intraorbital CSCC with perineural disease that involved all branches of the left trigeminal nerve to the cisternal portion. Despite 54Gy in 27 fractions of radiotherapy completed on December 2017, MRI scan in February 2018 revealed disease progression with increasing tumor anterior to the left frontal bone, new marrow infiltration of the floor of the left cranial fossa with nodular dural enhancement and no response in the pre-existing orbital disease (Figure 1D). After MDM discussion, he was referred for consideration of immunotherapy. He consented to trial participation in the NCT02760498 (cemiplimab 3 mg/kg Q2W). At Day 1 review, his ECOG performance status was assessed as 1 , and examination demonstrated a $25 \mathrm{~mm}$ left supraorbital mass, complete left eyelid proptosis, complete opthalmoplegia of his left eye, decreased sensation in the trigeminal nerve distribution with patient report of neuropathic pain. At Day 15 his pain had improved but he reported falls at home on the background of worsening balance, resulting in local trauma to the forehead. Clinical examination demonstrated no obvious abnormalities compared to baseline, however ECOG performance status was assessed as 2. Patient Three was referred for allied health management and received his second dose of cemiplimab. Two days later, he was admitted to hospital following a fall with a head strike with loss of consciousness, and reported nausea. CT brain (Day 21) identified disease progression (+44\%, iUPD) with enhancement of the left trigeminal nerve disease into the cerebellar peduncle and left-sided pons with surrounding edema. The patient was discharged mobilizing on a wheeled frame the following day. At Day 29 review, the patient reported a significant improvement in his neuropathic pain, the supraorbital mass was clinically smaller but his ECOG performance status was assessed as 2. Restaging CT scans performed (Day 50) identified ongoing disease progression with an increase in size in all target lesions (+42\% from baseline, RECIST 1.1 PD, iUPD). MRI brain demonstrated progression with increased diffuse skin thickening, increased enhancement of the orbital and periorbital disease, new destruction of the bones associated with the left frontal and ethmoid sinus and left orbit, soft tissue intracranial extension into the left anterior and middle cranial fossa, with increased trigeminal perineural invasion into the left brainstem. In clinic on Day 57, he reported a complete absence of trigeminal nerve pain and a reduction of the left supraorbital mass to $15 \mathrm{~mm}$ was noted. Treatment beyond progression was approved. By Day 104, imaging demonstrated ongoing RECIST PD (+28\%, iUPD) with subsequent review confirming regression of the exophytic component of the supraorbital CSCC and exposed bone. Patient Three went on to complete 659 days on therapy after experiencing a number of immune-related ( $\leq$ Grade 2 ) and other medical adverse events (not treatment-related). His most recent imaging of his target lesions (Figure 1D) demonstrated complete resolution of the pons lesion, stable orbital lesion and "not measurable" ulcerated left scalp lesion.

Two of the patient cases presented introduce a new phenomenon we have defined as a "delayed response after confirmed progression (DR)". That is, the observation of a clinical and radiological response after iCPD. In both cases, clinical deterioration was observed early in treatment but after treatment beyond progression, durable clinical and radiological improvement was obtained. In one case, change of tumor evolution with the cessation of new lesions developing may have been the only indication to herald DR. Review of our institutional experience of patients treated with cemiplimab on trial (up to $15 / \mathrm{SEP} / 2020$ ) in the advanced setting who have received more than one dose, demonstrates an estimated incidence of $2 / 39$ (5\%) of DR without any cases of "traditional pseudoprogression". We have observed DR occurring late in treatment courses and "traditional pseudoprogression" for nontrial patients. We also raise the concept that clinical deterioration may not militate against tumor response. In distinction to the three cases discussed where all patients experienced diseaserelated deterioration, the KEYNOTE-629 study which used RECIST 1.1 criteria for response evaluation reported that 29 clinically stable patients received treatment beyond progression (10). Of these, 12 patients continue on therapy and eight patients have developed responses (1 complete response, 7 partial responses according to irRECIST; FIG S4 (10)).

Therefore, our observation of DR and scenarios discussed further below, caution against a nihilistic approach to CSCC patient management when using immunotherapy. These cases highlight the important consideration of the timing and method of disease response assessments and the limitations of most criteria to capture pseudoprogression/DR, response rates and best overall response (BOR) assessments as part of clinical trial reporting. Use of the RECIST 1.1 framework will have not accurately reflected BOR for these patients, with the known limitation of most frameworks to act as a surrogate for progression-free and overall survival (25). Although the timing 
of imaging assessments are necessarily at a time point to permit sufficient receipt of therapy to assess response, these scans may not contemporaneously reflect disease evolution and response. Further, data from trials that utilize immunotherapy in the neoadjuvant setting prior to definitive surgery suggests that complete pathological responses may be seen only as partial response on imaging (26-29). This highlights the clinical need for research into the predictive and prognostic role of imaging techniques in patients treated with immunotherapy for CSCC and the need to identify relevant molecular liquid biopsy biomarkers for disease surveillance (30-32).

\section{SECOND PRIMARY TUMORS ON IMMUNOTHERAPY}

Multiplicity is common for patients with NMSC, with $\sim 74 \%$ of all skin cancers being excised from patients with multiple NMSC lesions particularly involving the head and neck region $(2,3)$. We have observed that patients on immunotherapy can develop both CSCC and BCC as second primary tumors (SPT) despite responsive disease elsewhere, likely due to field cancerization (33). The mechanism by which SPT escape treatment control have not yet been elucidated and are likely to illuminate molecular mechanisms behind immune escape.

From a clinical management perspective, it is critical that SPT development is not mistaken as treatment failure given that these lesions can resolve with ongoing therapy or can be managed with local therapy. As a general principle, the SPT should be observed for a period whilst continuing immunotherapy and if regression or stability does not occur then local therapy can be pursued with a view of continuing systemic therapy for control of the other immunotherapy-responsive disease. On retrospective review of our patients treated with cemiplimab on trial, of eight patients who developed biopsy proven SPT resistant to immunotherapy, seven patients with CSCC and six with BCC required formal excision and/or radiotherapy for local management with all but one patient having more than one lesion. We have not identified any situation for which the new SPT has resulted in metastatic disease or has heralded the development of disease progression in existing lesions. Molecular profiling of these SPTs that develop on immunotherapy is important to define disease heterogeneity and to identify the likely numerous mechanisms of immune escape.

\section{HETEROGENEOUS RESPONSES ON IMMUNOTHERAPY}

Discordant immunotherapy responses can be observed between existing lesions, where concurrent local therapy for immunotherapy-resistant lesions may be warranted to secure control. Given the common multiplicity of NMSCs occurring in the same patient (2), awareness of response heterogeneity is key to avoid inappropriate early cessation of immunotherapy.

\section{Case Four}

This case demonstrates heterogeneous responses of two baseline lesions to immunotherapy. Patient Four was a 70 year old man with a multiply recurrent CSCC of his left forearm which had required six re-excisions. The largest resected recurrence was a $70 \times 50 \mathrm{~mm}$ spindled/poorly differentiated CSCC, up to $8 \mathrm{~mm}$ in depth, with lymphovascular and perineural invasion. Adjuvant 56 Gy/28\# of radiotherapy was completed in September 2018, with a truncated course due to toxicity. In May 2019, Patient Four developed a painful locally recurrent CSCC of his left elbow with bone on view that measured $41 \times 32 \mathrm{~mm}$ on MRI scan, and a small right cheek lesion suspected to be a separate primary CSCC. Following MDM discussion, surgery for the cheek lesion was planned prior to immunotherapy for the elbow lesion. Wide local excision of the cheek lesion on the 26/JUN/ 2019 revealed three areas containing moderately differentiated CSCC spanning over $26 \mathrm{~mm}, 32 \mathrm{~mm}$ and $40 \mathrm{~mm}$ with a transected deep margin, multiple CSCC tissue deposits of $2 \mathrm{~mm}$ to $8 \mathrm{~mm}$, with perineural invasion abutting the margin. Re-excision was performed on 03/JUL/2019 revealing multiple foci of moderately differentiated CSCC deposits with perineural invasion, vascular tumor emboli, and tumor $0.2 \mathrm{~mm}$ from a margin. Patient Four consented to participation the NCT02760498. At baseline, the exophytic left elbow lesion clinically measured $70 x 35 \mathrm{~mm}$. Prior to the third dose (Day 57), a near complete clinical response of the left elbow CSCC was observed with a residual superficial ulcer measuring $10 \mathrm{~mm}$ accompanied by an improvement in pain. MRI scan confirmed the lesion had reduced to $32 \times 13 \mathrm{~mm}$. A month later (Day 87 ) a right cheek nodule recurred and given its persistence, resection was performed on Day 106 demonstrating an $11 \mathrm{~mm}$ CSCC with $\leq 1 \mathrm{~mm}$ margins. Ongoing immunotherapy secured a complete clinical response for the left elbow lesion by Day 141 with imaging showing no identifiable tumor (nominal RECIST measurement of $5 \mathrm{~mm}$ ). However, three further excisions (Day 147 , Day 188, Day 218) were required to manage the cheek lesion which recurred twice during adjuvant radiotherapy planning. Palliative radiotherapy of $36 \mathrm{~Gy}$ in $6 \#$ to the cheek lesion was completed on Day 283. Most recent imaging demonstrated a complete metabolic response (Day 335) and ongoing radiological PR (nominal 5mm, Day 447) of the left elbow disease. However, since Day 394 clinical recurrence of the right cheek nodule has been progressive. Due to the absence of local therapies available to effectively treat the recurrent right cheek CSCC, Patient Four decided to cease further immunotherapy to pursue best supportive care.

Tumoral heterogeneity leading to discordant treatment response is a known therapeutic hurdle that can contribute to disease progression with the development of clonal resistance (34-38). In the era of immunotherapy which can secure durable disease control, understanding the contribution of local therapy towards overall disease control and survival is crucial but poorly understood. It has been observed in patients with melanoma treated with immunotherapy who received local therapy to progressive lesions in order to achieve no evidence of disease, that those who had local therapy to new lesions had poorer 
survival compared to those who had local therapy to progressive pre-existing metastases (PFS 6\% vs 70\%, p=0.001) (39). Consideration of the anatomical site of oligoclonal resistant disease will have clinical (e.g. brain versus lung) and therapeutic implications (e.g. surgery versus radiotherapy). Patient Four's case demonstrates that discordant immunotherapy responses can be observed between lesions, where concurrent local therapy may be warranted in an attempt to secure control of immunotherapyresistant lesions.

\section{EXPANDING CLINICAL BOUNDARIES - ACTIVITY IN ADVANCED, FUNGATING, DISFIGURING DISEASE AND GOOD TOLERANCE DESPITE MULTIPLE COMORBIDITIES}

It is essential to consider patient factors, treatment morbidity and goals of management in oncological care. Comorbidities and
A

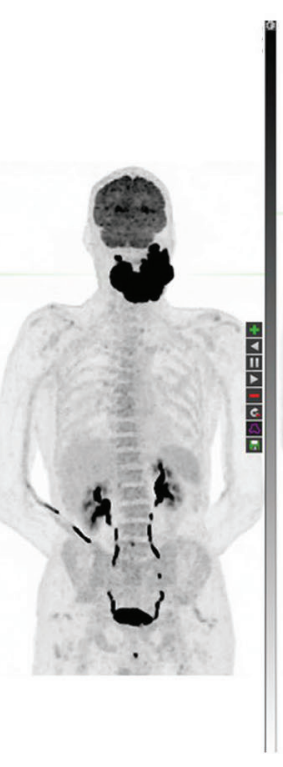

B

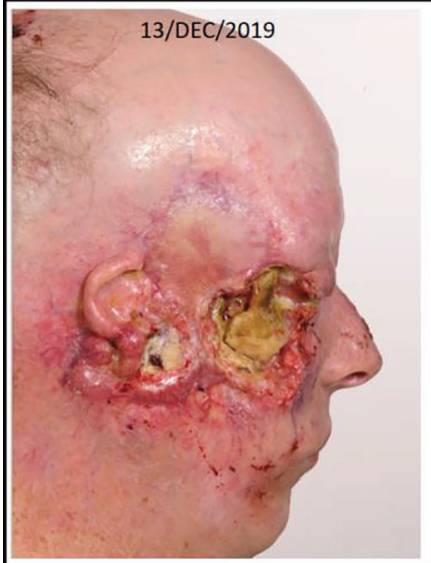

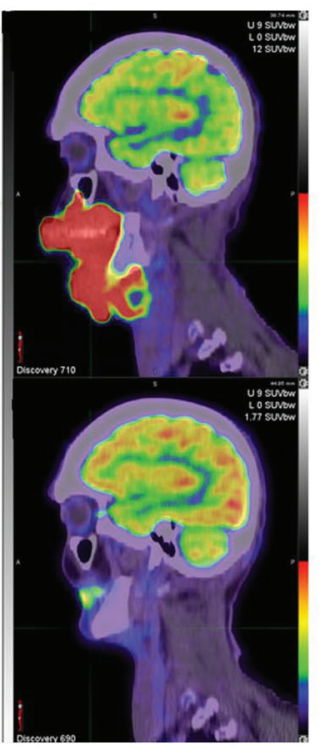

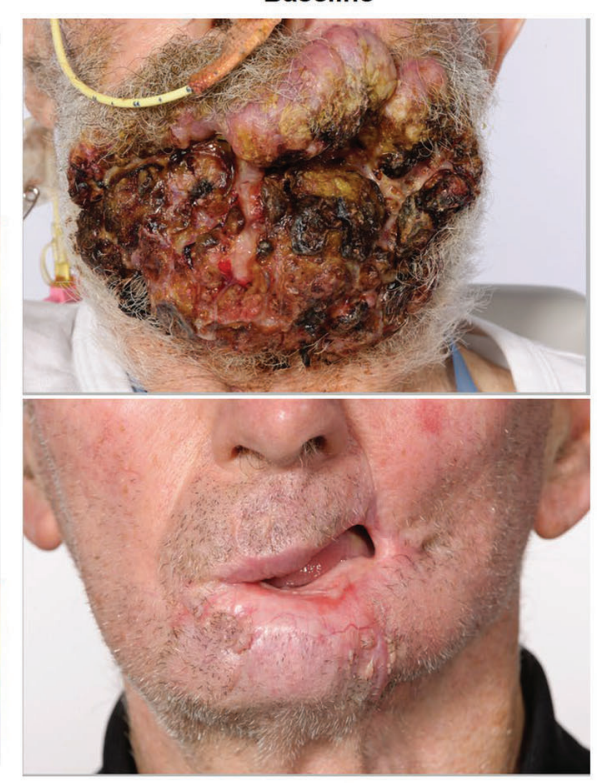

Day 360

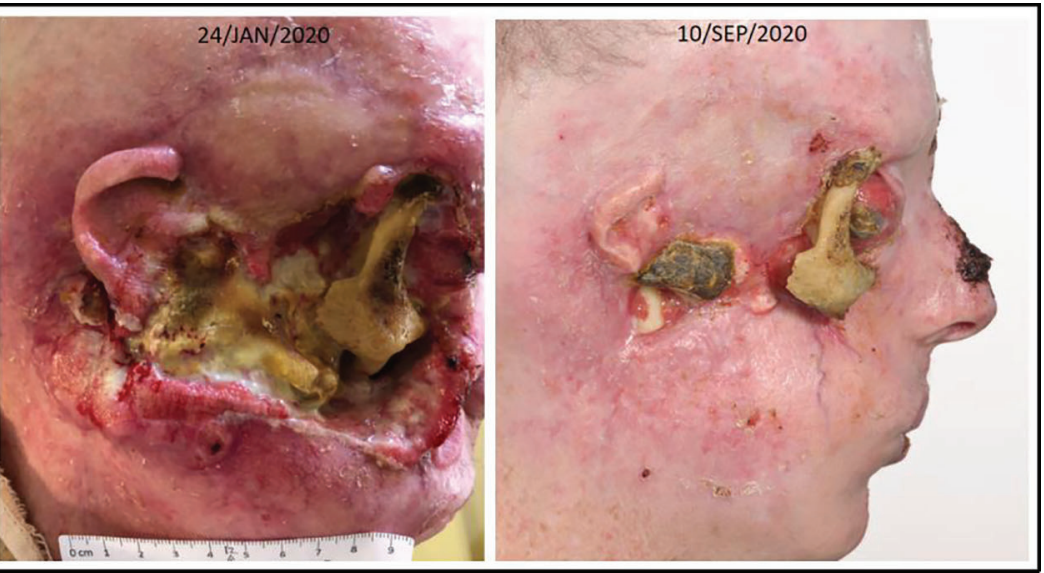

FIGURE 2 | (A) This figure illustrates the FDG-PET matched MIP and fused axial images with photographs at baseline and after receipt of cemiplimab of a 75-year-old male who had declined investigation and treatment of CSCC originating from his chin. After 18 months of pursuing alternative treatment, he accepted immunotherapy when the disease had become so advanced it mechanically impacted his ability to eat. He consented to participation in the NCT02760498, and after receipt of two doses clinical regression of the lesion was noted. His disease remains in complete remission after two years of therapy completed more than 12 months ago. (B) This figure illustrates re-epithelialization occurring during the receipt of compassionate access cemiplimab in a 45-year-old patient with more than a 20 year history of multiple NMSC including synchronous CSCC, BCC and MCC. The patient ceased vismodegib to commence cemiplimab on 13/DEC/2019 but required recommencement of vismodegib on 19/APR/2020 due to recurrence of multiple BCC lesions. He remains on dual therapy given the symptomatic improvement achieved with good pain control and resolution of right cheek CSCC-related trismus. 
ECOG performance status guide management to optimize patient outcomes that may focus on quality of life or may be driven to obtain survival benefits or both. It is well recognized that a large disparity exists between trial patients versus "real-world" patients, who often are older, of minority groups, and with comorbidities that may interfere with assessment of therapeutic efficacy or toxicity $(40)(41,42)$. In the context of the functionally and cosmetically sensitive anatomical region of the head and neck, it is crucial to define that immunotherapy is generally tolerable and associated with improved quality of life $(22,43,44)$. In CSCC, Maubec et al. have reported improved health-related quality of life for patients with immunotherapy-responsive disease (11), and use of PD-1 blockade has been demonstrated to be tolerable with side effects reported similar to other checkpoint inhibitors and with the ability to secure durable disease control $(7,9,45)$. Noteworthy in the trial reports, is the median age of patients being 71-80 years with the oldest patients being 99 years old (7, 10, 11).

Our institutional experience in the trial and "real-world" setting is that checkpoint inhibitor therapy is exceptionally well tolerated by patients with CSCC. Generally, few treatment contraindications exist and few comorbidities raise concern including extreme age, dialysis, other synchronous malignancies requiring treatment, and poor ECOG performance status. This is a paradigm change in our approach to patients with CSCC and is paramount given the dramatic response rates achieved by therapy, providing symptomatic and durable control. This is in stark contradistinction to our approach with mucosal head and neck cancer patients. As illustrated in Figure 2, there are not many clinical situations in which disease is considered "too advanced" for immunotherapy. That is, the stage of disease, location of disease, and extent of disease does not militate against response to immunotherapy. Anecdotally, the extent of re-epithelialization following response can be impressive creating complexity around the timing of reconstructive surgery if pursued.

\section{CONCLUSION AND FUTURE DIRECTIONS}

Use of immunotherapy has revolutionized the care of patients with advanced CSCC, leading to a paradigm shift in the selection of patients for treatment with the expectation of response and durable control even in the advanced recurrent or metastatic setting. We have focused on describing unique clinical concepts related to the treatment of CSCC with immunotherapy including the phenomenon of delayed response after confirmed progression (DR), observation of tumor responses despite clinical deterioration in $\mathrm{ICPD}$, and the need to consider flexible treatment approaches in patients with multiple NMSC.

An improved understanding of CSCC will undoubtedly enhance patient selection for therapy as ongoing clinical research efforts investigate the role of immunotherapy in the adjuvant and neoadjuvant settings. Few cancer registries collect data on CSCC or advanced CSCC, limiting our understanding of the spectrum of disease, burden of need, morbidity and costs related to treatment. The therapeutic advances necessitate rapid development of real-time methods to assess tumor response (e.g. liquid biopsy, imaging or combination approaches) that are more informative than current imaging modalities and response criteria. Translational research will be crucial to molecularly define the clinical spectrum of $\operatorname{CSCC}(46,47)$, and identify reliable predictive and prognostic markers to therapy, including mechanisms of immune evasion. Specifically, comprehensive profiling of immunotherapy exposed tumors, including single cell sequencing approaches, will be important to further clarify inter-tumoral, intra-tumoral and tumor microenvironment molecular processes that underpin the described clinical concepts $(48,49)$.

\section{DATA AVAILABILITY STATEMENT}

The original contributions presented in the study are included in the article. Further inquiries can be directed to the corresponding author.

\section{ETHICS STATEMENT}

The studies involving human participants were reviewed and approved by Peter MacCallum Cancer Centre Ethics Committee. Written consent has been provided by the patient with reidentifiable images.

\section{AUTHOR CONTRIBUTIONS}

Concept and design - AL, DR. All authors contributed to the article and approved the submitted version.

\section{FUNDING}

DR is supported by a NHMRC Investigator Grant APP1175929.

\section{ACKNOWLEDGMENTS}

Regeneron and Sanofi have reviewed the manuscript prior to publication but have not contributed or modified the manuscript in any substantial way. We thank all the patients and families, who have received treatment at our center. We thank our clinical trial team members who have contributed significantly to patient care. 


\section{REFERENCES}

1. Bray F, Ferlay J, Soerjomataram I, Siegel RL, Torre LA, Jemal A. Global cancer statistics 2018: GLOBOCAN estimates of incidence and mortality worldwide for 36 cancers in 185 countries. CA Cancer J Clin (2018) 68(6):394-424. doi: $10.3322 /$ caac. 21492

2. Pandeya N, Olsen CM, Whiteman DC. The incidence and multiplicity rates of keratinocyte cancers in Australia. Med J Aust (2017) 207(8):339-43. doi: 10.5694/mja17.00284

3. Richmond-Sinclair NM, Pandeya N, Ware RS, Neale RE, Williams GM, van der Pols JC, et al. Incidence of Basal Cell Carcinoma Multiplicity and Detailed Anatomic Distribution: Longitudinal Study of an Australian Population. J Invest Dermatol (2009) 129(2):323-8. doi: 10.1038/jid.2008.234

4. Australian Institute of Health and Welfare 2019. Cancer in Australia 2019. Cancer series no.119. Cat. no. CAN 123. Canberra: AIHW (2019).

5. Brantsch KD, Meisner C, Schonfisch B, Trilling B, Wehner-Caroli J, Rocken $\mathrm{M}$, et al. Analysis of risk factors determining prognosis of cutaneous squamous-cell carcinoma: a prospective study. Lancet Oncol (2008) 9 (8):713-20. doi: 10.1016/S1470-2045(08)70178-5

6. Nakamura K, Okuyama R, Saida T, Uhara H. Platinum and anthracycline therapy for advanced cutaneous squamous cell carcinoma. Int $J$ Clin Oncol (2013) 18(3):506-9. doi: 10.1007/s10147-012-0411-y

7. Migden MR, Rischin D, Schmults CD, Guminski A, Hauschild A, Lewis KD, et al. PD-1 Blockade with Cemiplimab in Advanced Cutaneous SquamousCell Carcinoma. N Engl J Med (2018) 379(4):341-51. doi: 10.1056/ NEJMoa1805131

8. Migden MR, Khushalani NI, Chang ALS, Lewis KD, Schmults CD, HernandezAya L, et al. Cemiplimab in locally advanced cutaneous squamous cell carcinoma: results from an open-label, phase 2, single-arm trial. Lancet Oncol (2020) 21(2):294-305. doi: 10.1016/s1470-2045(19)30728-4

9. Rischin D, Khushalani NI, Schmults CD, Guminski AD, Chang ALS, Lewis KD, et al. Phase II study of cemiplimab in patients (pts) with advanced cutaneous squamous cell carcinoma (CSCC): Longer follow-up. J Clin Oncol (2020) 38(15_suppl):10018-. doi: 10.1200/JCO.2020.38. 15_suppl.10018

10. Grob JJ, Gonzalez R, Basset-Seguin N, Vornicova O, Schachter J, Joshi A, et al. Pembrolizumab Monotherapy for Recurrent or Metastatic Cutaneous Squamous Cell Carcinoma: A Single-Arm Phase II Trial (KEYNOTE-629). J Clin Oncol Off J Am Soc Clin Oncol (2020) 38(25):2916-25. doi: 10.1200/ JCO.19.03054

11. Maubec E, Boubaya M, Petrow P, Beylot-Barry M, Basset-Seguin N, Deschamps L, et al. Phase II Study of Pembrolizumab As First-Line, SingleDrug Therapy for Patients With Unresectable Cutaneous Squamous Cell Carcinomas. J Clin Oncol Off J Am Soc Clin Oncol (2020) 38(26):3051-61. doi: 10.1200/JCO.19.03357

12. Eisenhauer EA, Therasse P, Bogaerts J, Schwartz LH, Sargent D, Ford R, et al. New response evaluation criteria in solid tumours: revised RECIST guideline (version 1.1). Eur J Cancer (2009) 45(2):228-47. doi: 10.1016/ j.ejca.2008.10.026

13. Di Giacomo AM, Danielli R, Guidoboni M, Calabrò L, Carlucci D, Miracco C, et al. Therapeutic efficacy of ipilimumab, an anti-CTLA-4 monoclonal antibody, in patients with metastatic melanoma unresponsive to prior systemic treatments: clinical and immunological evidence from three patient cases. Cancer Immunol Immunother (2009) 58(8):1297-306. doi: 10.1007/s00262-008-0642-y

14. Llovet JM, Ricci S, Mazzaferro V, Hilgard P, Gane E, Blanc JF, et al. Sorafenib in advanced hepatocellular carcinoma. N Engl J Med (2008) 359(4):378-90. doi: 10.1056/NEJMoa0708857

15. Choi H, Charnsangavej C, Faria SC, Macapinlac HA, Burgess MA, Patel SR, et al. Correlation of computed tomography and positron emission tomography in patients with metastatic gastrointestinal stromal tumor treated at a single institution with imatinib mesylate: proposal of new computed tomography response criteria. J Clin Oncol Off J Am Soc Clin Oncol (2007) 25(13):1753-9. doi: 10.1200/JCO.2006.07.3049

16. Wolchok JD, Hoos A, O’Day S, Weber JS, Hamid O, Lebbé C, et al. Guidelines for the Evaluation of Immune Therapy Activity in Solid Tumors: ImmuneRelated Response Criteria. Clin Cancer Res (2009) 15(23):7412-20. doi: 10.1158/1078-0432.Ccr-09-1624
17. Seymour L, Bogaerts J, Perrone A, Ford R, Schwartz LH, Mandrekar S, et al. iRECIST: guidelines for response criteria for use in trials testing immunotherapeutics. Lancet Oncol (2017) 18(3):e143-e52. doi: 10.1016/ S1470-2045(17)30074-8

18. Wolchok JD, Hoos A, O'Day S, Weber JS, Hamid O, Lebbe C, et al. Guidelines for the evaluation of immune therapy activity in solid tumors: immune-related response criteria. Clin Cancer Res (2009) 15(23):7412-20. doi: 10.1158/10780432.CCR-09-1624

19. Nishino M, Giobbie-Hurder A, Gargano M, Suda M, Ramaiya NH, Hodi FS. Developing a common language for tumor response to immunotherapy: immune-related response criteria using unidimensional measurements. Clin Cancer Res (2013) 19(14):3936-43. doi: 10.1158/10780432.Ccr-13-0895

20. Hodi FS, Ballinger M, Lyons B, Soria JC, Nishino M, Tabernero J, et al. Immune-Modified Response Evaluation Criteria In Solid Tumors (imRECIST): Refining Guidelines to Assess the Clinical Benefit of Cancer Immunotherapy. J Clin Oncol Off J Am Soc Clin Oncol (2018) 36(9):850-8. doi: 10.1200/JCO.2017.75.1644

21. Chiou VL, Burotto M. Pseudoprogression and Immune-Related Response in Solid Tumors. J Clin Oncol Off J Am Soc Clin Oncol (2015) 33(31):3541-3. doi: 10.1200/JCO.2015.61.6870

22. Ferris RL, Blumenschein GJr, Fayette J, Guigay J, Colevas AD, Licitra L, et al. Nivolumab for Recurrent Squamous-Cell Carcinoma of the Head and Neck. N Engl J Med (2016) 375(19):1856-67. doi: 10.1056/NEJMoa1602252

23. Seiwert TY, Burtness B, Mehra R, Weiss J, Berger R, Eder JP, et al. Safety and clinical activity of pembrolizumab for treatment of recurrent or metastatic squamous cell carcinoma of the head and neck (KEYNOTE-012): an openlabel, multicentre, phase 1b trial. Lancet Oncol (2016) 17(7):956-65. doi: 10.1016/S1470-2045(16)30066-3

24. Long GV, Weber JS, Larkin J, Atkinson V, Grob J-J, Schadendorf D, et al. Nivolumab for Patients With Advanced Melanoma Treated Beyond Progression: Analysis of 2 Phase 3 Clinical Trials. JAMA Oncol (2017) 3 (11):1511-9. doi: 10.1001/jamaoncol.2017.1588

25. Mushti SL, Mulkey F, Sridhara R. Evaluation of Overall Response Rate and Progression-Free Survival as Potential Surrogate Endpoints for Overall Survival in Immunotherapy Trials. Clin Cancer Res (2018) 24(10):2268-75. doi: 10.1158/1078-0432.Ccr-17-1902

26. Tarhini A, Lin $\mathrm{Y}$, Lin $\mathrm{H}$, Rahman $\mathrm{Z}$, Vallabhaneni $\mathrm{P}$, Mendiratta $\mathrm{P}$, et al. Neoadjuvant ipilimumab $(3 \mathrm{mg} / \mathrm{kg}$ or $10 \mathrm{mg} / \mathrm{kg}$ ) and high dose IFN- $\alpha 2 \mathrm{~b}$ in locally/regionally advanced melanoma: safety, efficacy and impact on T-cell repertoire. J immunother Cancer (2018) 6(1):112-. doi: 10.1186/s40425-0180428-5

27. Rozeman EA, Menzies AM, van Akkooi ACJ, Adhikari C, Bierman C, van de Wiel BA, et al. Identification of the optimal combination dosing schedule of neoadjuvant ipilimumab plus nivolumab in macroscopic stage III melanoma (OpACIN-neo): a multicentre, phase 2, randomised, controlled trial. Lancet Oncol (2019) 20(7):948-60. doi: 10.1016/s1470-2045(19)30151-2

28. Blank CU, Rozeman EA, Fanchi LF, Sikorska K, van de Wiel B, Kvistborg P, et al. Neoadjuvant versus adjuvant ipilimumab plus nivolumab in macroscopic stage III melanoma. Nat Med (2018) 24(11):1655-61. doi: 10.1038/s41591-018-0198-0

29. Amaria RN, Reddy SM, Tawbi HA, Davies MA, Ross MI, Glitza IC, et al. Neoadjuvant immune checkpoint blockade in high-risk resectable melanoma. Nat Med (2018) 24(11):1649-54. doi: 10.1038/s41591-018-0197-1

30. Tan AC, Emmett L, Lo S, Liu V, Kapoor R, Carlino MS, et al. FDG-PET response and outcome from anti-PD-1 therapy in metastatic melanoma. Ann Oncol (2018) 29(10):2115-20. doi: 10.1093/annonc/mdy330

31. Tie J, Wang Y, Tomasetti C, Li L, Springer S, Kinde I, et al. Circulating tumor DNA analysis detects minimal residual disease and predicts recurrence in patients with stage II colon cancer. Sci Transl Med (2016) 8(346):346ra92. doi: 10.1126/scitranslmed.aaf6219

32. Bensch F, van der Veen EL, Lub-de Hooge MN, Jorritsma-Smit A, Boellaard $\mathrm{R}$, Kok IC, et al. 89Zr-atezolizumab imaging as a non-invasive approach to assess clinical response to PD-L1 blockade in cancer. Nat Med (2018) 24 (12):1852-8. doi: 10.1038/s41591-018-0255-8

33. Christensen SR. Recent advances in field cancerization and management of multiple cutaneous squamous cell carcinomas. F1000Res (2018) 7:F1000 Faculty Rev-690. doi: 10.12688/f1000research.12837.1 
34. Wolf Y, Bartok O, Patkar S, Eli GB, Cohen S, Litchfield K, et al. UVB-Induced Tumor Heterogeneity Diminishes Immune Response in Melanoma. Cell (2019) 179(1):219-35.e21. doi: 10.1016/j.cell.2019.08.032

35. Aslan K, Turco V, Blobner J, Sonner JK, Liuzzi AR, Núñez NG, et al. Heterogeneity of response to immune checkpoint blockade in hypermutated experimental gliomas. Nat Commun (2020) 11(1):931. doi: 10.1038/s41467020-14642-0

36. Lu LC, Hsu C, Shao YY, Chao Y, Yen CJ, Shih IL, et al. Differential OrganSpecific Tumor Response to Immune Checkpoint Inhibitors in Hepatocellular Carcinoma. Liver Cancer (2019) 8(6):480-90. doi: 10.1159/000501275

37. Seiwert TY, Kiess AP. Time to Debunk an Urban Myth? The "Abscopal Effect" With Radiation and Anti-PD-1. J Clin Oncol Off J Am Soc Clin Oncol (2021) 39(1):1-3. doi: 10.1200/jco.20.02046

38. McBride S, Sherman E, Tsai CJ, Baxi S, Aghalar J, Eng J, et al. Randomized Phase II Trial of Nivolumab With Stereotactic Body Radiotherapy Versus Nivolumab Alone in Metastatic Head and Neck Squamous Cell Carcinoma. J Clin Oncol Off J Am Soc Clin Oncol (2021) 39(1):30-7. doi: 10.1200/ jco. 20.00290

39. Klemen ND, Wang M, Feingold PL, Cooper K, Pavri SN, Han D, et al. Patterns of failure after immunotherapy with checkpoint inhibitors predict durable progression-free survival after local therapy for metastatic melanoma. J ImmunoTher Cancer (2019) 7(1):196. doi: 10.1186/ s40425-019-0672-3

40. Leonardi GC, Gainor JF, Altan M, Kravets S, Dahlberg SE, Gedmintas L, et al. Safety of Programmed Death-1 Pathway Inhibitors Among Patients With Non-Small-Cell Lung Cancer and Preexisting Autoimmune Disorders. J Clin Oncol (2018) 36(19):1905-12. doi: 10.1200/jco.2017.77.0305

41. Murthy VH, Krumholz HM. Gross CP. Participation in Cancer Clinical TrialsRace-, Sex-, and Age-Based Disparities. JAMA (2004) 291(22):2720-6. doi: 10.1001/jama.291.22.2720

42. Ludmir EB, Mainwaring W, Lin TA, Miller AB, Jethanandani A, Espinoza AF, et al. Factors Associated With Age Disparities Among Cancer Clinical Trial Participants. JAMA Oncol (2019) 5(12):1769-73. doi: 10.1001/ jamaoncol.2019.2055

43. Cohen EEW, Soulieres D, Tourneau CL, Dinis J, Licitra LF, Ahn M-J, et al. Health-related quality of life (HRQoL) of pembrolizumab (pembro) vs standard of care (SOC) for recurrent/metastatic head and neck squamous cell carcinoma (R/M HNSCC) in KEYNOTE-040. J Clin Oncol (2018) 36 (15_suppl):6013-. doi: 10.1200/JCO.2018.36.15_suppl.6013

44. Cohen EEW, Bell RB, Bifulco CB, Burtness B, Gillison ML, Harrington KJ, et al. The Society for Immunotherapy of Cancer consensus statement on immunotherapy for the treatment of squamous cell carcinoma of the head and neck (HNSCC). J immunother Cancer (2019) 7(1):184-. doi: 10.1186/s40425019-0662-5
45. Rischin D, Migden MR, Lim AM, Schmults CD, Khushalani NI, Hughes BGM, et al. Phase 2 study of cemiplimab in patients with metastatic cutaneous squamous cell carcinoma: primary analysis of fixed-dosing, long-term outcome of weight-based dosing. J Immunother Cancer (2020) 8(1). doi: 10.1136/jitc-2020-000775

46. Ji AL, Rubin AJ, Thrane K, Jiang S, Reynolds DL, Meyers RM, et al. Multimodal Analysis of Composition and Spatial Architecture in Human Squamous Cell Carcinoma. Cell (2020) 182(2):497-514.e22. doi: 10.1016/ j.cell.2020.05.039

47. Frazzette N, Khodadadi-Jamayran A, Doudican N, Santana A, Felsen D, Pavlick AC, et al. Decreased cytotoxic T cells and TCR clonality in organ transplant recipients with squamous cell carcinoma. NPJ Precis Oncol (2020) 4 (1):13. doi: 10.1038/s41698-020-0119-9

48. Stewart CA, Gay CM, Xi Y, Sivajothi S, Sivakamasundari V, Fujimoto J, et al. Single-cell analyses reveal increased intratumoral heterogeneity after the onset of therapy resistance in small-cell lung cancer. Nat Cancer (2020) 1:423-36. doi: 10.1038/s43018-019-0020-Z

49. Wang R, Dang M, Harada K, Han G, Wang F, Pool Pizzi M, et al. Single-cell dissection of intratumoral heterogeneity and lineage diversity in metastatic gastric adenocarcinoma. Nat Med (2021) 27(1):141-51. doi: 10.1038/s41591020-1125-8

Conflict of Interest: AL -Uncompensated advisory board7 from Merck Sharp \& Dohme and Bristol-Myers Squibb with travel and accommodation expenses; uncompensated consultancy for Eisai. RH - Shareholder in Telix Pharmaceuticals with honoraria and any dividends donated to the Peter MacCallum Cancer Centre. DR - Institutional research grant and trial funding from Regeneron Pharmaceuticals, Inc., Roche, Merck Sharp \& Dohme, BristolMyers Squibb, and GlaxoSmithKline, Sanofi; uncompensated scientific committee and advisory board from Merck Sharp \& Dohme, Regeneron Pharmaceuticals, Inc., Sanofi, GlaxoSmithKline, and Bristol-Myers Squibb, and travel and accommodation from Merck Sharp \& Dohme and GlaxoSmithKline.

The remaining authors declare that the research was conducted in the absence of any commercial or financial relationships that could be construed as a potential conflict of interest.

Copyright (C) 2021 Lim, Cavanagh, Hicks, McLean, Goh, Webb and Rischin. This is an open-access article distributed under the terms of the Creative Commons Attribution License (CC BY). The use, distribution or reproduction in other forums is permitted, provided the original author(s) and the copyright owner(s) are credited and that the original publication in this journal is cited, in accordance with accepted academic practice. No use, distribution or reproduction is permitted which does not comply with these terms. 